\title{
Ressecção de Cordoma Sacral com Abaixamento de Cólon: Relato de Caso
}

\section{Sacral Chordoma Resection With Colo Anal Anastomosis: Case Report}

\author{
KANTHYA ARREGUY DE SENA*; FÁBIO LOPES DE QUEIROZ*; LEONARDO SILLUZIO FERREIRA**; \\ RAMON TEODORO SILVEIRA**; ISABELA PESSOA ELIAS*; FREDERICO GUSMÃO CÂMARA*; \\ ANTÔNIO LACERDA FILHO*
}

SENA KA; QUEIROZ FL; FERREIRA LS; SILVEIRA RT; ELIAS IP; CÂMARA FG; LACERDA FILHO A. Ressecção de Cordoma Sacral com Abaixamento de Cólon: Relato de Caso Rev bras Coloproct, 2006;26(3): 321-324.

RESUMO: O cordoma é uma lesão maligna da medula espinhal, que se origina nos remanescentes ectópicos de tecido notocordial. Trata-se de neoplasia rara e sua localização preferencial é o sacro. Tem crescimento lento, mas comportamento localmente agressivo. Relatamos um caso de ressecção de cordoma sacral com abaixamento de cólon. Para extirpação oncológica da lesão foi necessária a abordagem colorretal e ortopédica. Novas técnicas preconizando cirurgias mais agressivas melhoraram significativamente a expectativa de vida dos pacientes portadores de cordoma, bem como o tempo de vida livre de doença. Na busca dessa cirurgia oncológica ideal, a abordagem multidisciplinar é essencial.

Descritores: Cordoma sacral; abordagem multidisciplinar.

O cordoma é uma lesão maligna que se origina nos remanescentes notocordiais e, por isso, localiza-se quase sempre no esqueleto axial. Aparece freqüentemente nas extremidades cefálica e caudal da coluna vertebral. Cerca de 50\% localiza-se na região sacral e constitui a neoplasia primária mais comum dessa região. É cerca de duas vezes mais freqüente no sexo masculino e ocorre predominantemente da $5^{\text {a }}$ à $7^{\text {a }}$ décadas de vida, apresentando crescimento lento com baixo poder metastatizante. Sua evolução desfavorável decorre do seu comportamento localmente agressivo e da sua proximidade com a medula espinhal e a cauda eqüina que prejudicam o controle cirúrgico da doença.

Relatamos um caso de ressecção oncológica multidisciplinar de cordoma sacral com abaixamento de cólon por via abdomino-sacral.

\section{RELATO DE CASO}

Paciente do sexo masculino, 62 anos, procurou avaliação médica devido a dor em região lombossacra de forte intensidade e de caráter progressivo nos 6 meses anteriores à consulta, que aliviava parcialmente com uso de antiinflamatórios não esteróides e analgésicos comuns. Relatava ainda sangramento anal ocasional durante evacuação e algúria. Ao exame proctológico, percebia-se mucosa retal íntegra, mas abaulada por lesão arredondada, subestenosante, a $7 \mathrm{~cm}$ da margem anal. Ao exame ortopédico não se percebia déficit motor ou sensitivo. Tomografia abdominal mostrou lesão óssea lítica na pelve. Ressonância magnética (RM) de sacro mostrou grande massa retro-retal com infiltração óssea de cóccix, S5, S4 e S3, medindo 8 × 6,1 x 9 cm e com compo-

\footnotetext{
* Trabalho realizado no Serviço de Coloproctologia do Hospital Felício Rocho - Belo Horizonte - Minas Gerais - Brasil.

** Serviço de Ortopedia e Traumatologia do Hospital Felício Rocho - Belo Horizonte - Minas Gerais - Brasil.

$\overline{\text { Recebido em 08/03/2006 }}$

Aceito para publicação em 12/04/2006
} 
nente extracortical se estendendo para a pelve em íntimo contato com o reto, mas sem evidências de invasão do mesmo. Ausência de infiltração das demais estruturas pélvicas ou linfonodomegalia associada (Figura 1).

Realizado tratamento cirúrgico com equipe multidisciplinar (Cirurgia Colorretal e Ortopedia). Em função do íntimo contato entre o tumor e a parede posterior do reto, optou-se pela abordagem abdominossacral para ressecção do tumor e do reto ,mantendo a integridade da pseudocápsula tumoral.

O paciente foi submetido a analgesia peridural e anestesia geral, balanceada com monitorização contínua invasiva, e posicionado em decúbito dorsal horizontal (DDH). Realizada laparotomia mediana suprainfra-umbilical com identificação da porção distal do reto firmemente aderida à fascia pré-sacral. Liberado cólon esquerdo da goteira parieto-cólica e ligadura dos vasos mesentéricos inferiores para abaixamento do ângulo esplênico do cólon. Seccionado cólon esquerdo ao nível da transição com o sigmóide com preservação da arcada vascular. Protegidos cotos colônicos para prevenção de contaminação. Dissecção anterior e lateral do reto com identificação dos ureteres, bexiga e vesículas seminais até o nível do assoalho pélvico, guiada por abordagem perineal. Posicionado paciente em

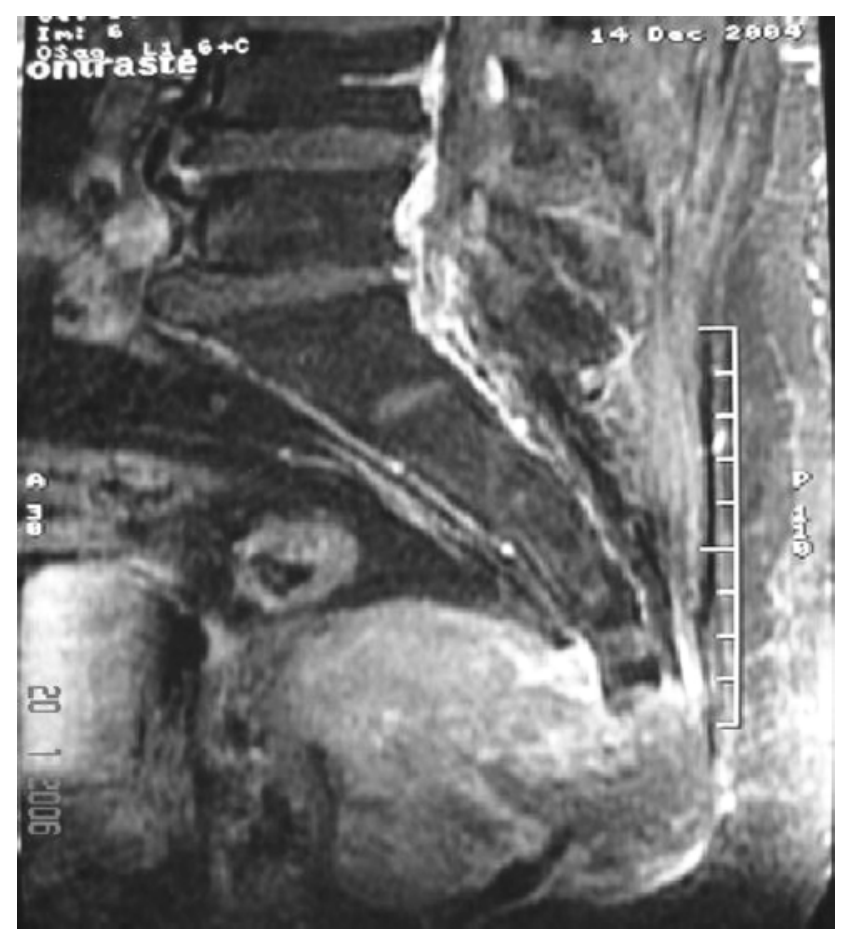

Figura 1 - Ressonância magnética de sacro: massa expansiva pélvica compatível com cordoma. decúbito ventral com flexão de $70^{\circ}$ ao nível da coluna lombar. Marcação por radioscopia, segundo imagens da RM, do nível da secção sacral. Ressecção ampliada de pele, tecido celular subcutâneo e musculatura da região glútea até identificação do segmento ósseo com retirada de toda a peça cirúrgica em monobloco (Figura 2). Com o paciente novamente em DDH, feito abaixamento do cólon com anastomose grampeada coloanal. Revisão dos procedimentos e hemostasia. Posicionamento de dreno pélvico, confecção de ileostomia protetora em flanco direito e laparorrafia por planos. O tempo cirúrgico total foi de 9 horas e o paciente manteve estabilidade hemodinâmica, tendo recebido $600 \mathrm{ml}$ de concentrado de hemácias, 11 litros de cristalóides e 2 litros de colóides. As primeiras 48 horas de pós-operatório foram monitoradas em nível de CTI. A evolução pós-operatória foi satisfatória e o paciente permaneceu hospitalizado por 11 dias. Não houve seqüelas motoras. Apresentou retenção urinária, necessitando sondagem vesical de alívio por cerca de 1 mês após a retirada da sonda de demora.

Estudo anatomopatológico mostrou peça cirúrgica medindo $18 \times 17 \times 11 \mathrm{~cm}$ constituída por tecidos cutâneo, adiposo e músculo-esquelético com segmentos de osso sacral (S5, S4 e S3) e de intestino grosso (Figura 3). Os cortes histológicos identificaram tumoração branco-amarelada com áreas de tecido fibroso, tecido mixocondróide e focos de necrose compatíveis com cordoma, envolvendo o osso sacral e infiltrando partes moles e tecido muscular. A parede do reto encontrava-se firmemente aderida à lesão, mas livre de neoplasia.

Realizou-se o fechamento da ileostomia no $3^{\circ}$ mês de pós-operatório sem intercorrências. No acompanhamento ambulatorial, o paciente encontra-se sem queixas álgicas e assintomático do ponto de vista urinário, mas nega ereção. Apresenta hipoestesia em região perianal e hipotonia esfincteriana moderada.

\section{DISCUSSÃO}

O cordoma sacral é um tumor de crescimento lento. Ele pode estender-se em direção proximal no canal medular ou pode destruir o osso sacral e acometer os tecidos frouxos adjacentes e a junção sacro-ilíaca. $\mathrm{O}$ periósteo e a fáscia pré-sacral constituem barreiras anatômicas à progressão anterior do tumor. Esse comportamento insidioso e seus sintomas inespecíficos freqüentemente atrasam o diagnóstico ${ }^{6}$. O tempo mé- 


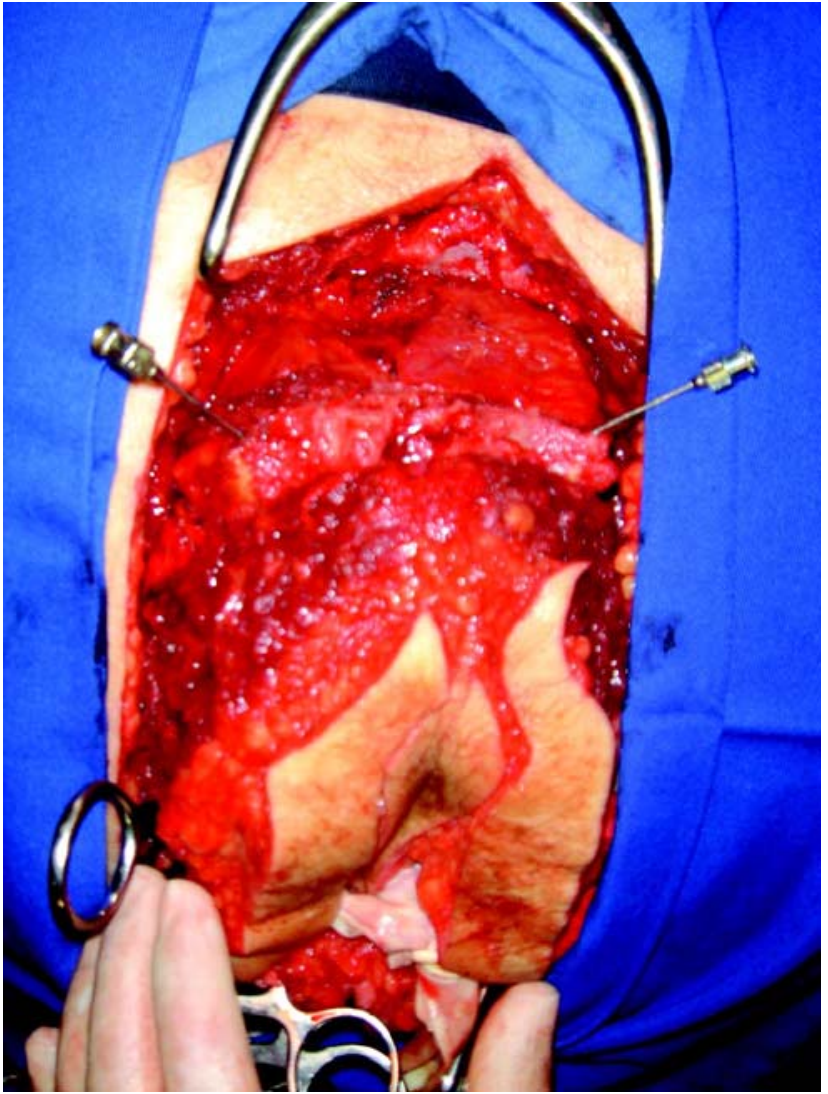

Figura 2 - Ressecção posterior com paciente posicionado em decúbito ventral com flexão de $70^{\circ}$ ao nível da coluna lombar. Hastes de metal na parte superior representam marcação por radioscopia, segundo imagens da RM, do nível da secção sacral.

dio entre o início dos sintomas e o diagnóstico varia de 4 a 24 meses. O sintoma mais comumente produzido pelo cordoma é a dor secundária à destruição óssea e/ ou compressão dos nervos ou órgãos adjacentes ${ }^{4}$. Ao diagnóstico, os cordomas sacrais são geralmente estagiados em IB ${ }^{1}$ com o tumor protundindo anteriormente a parede do reto, sem, no entanto, infiltrá-lo.

Na propedêutica pré-operatória, torna-se essencial a determinação do nível de invasão tumoral e, neste sentido, alguns trabalhos têm mostrado a superioridade da RM em relação à tomografia. Imagens de RM em T1 têm boa resolução para detecção de infiltração do canal medular e em T2 mostram, adequadamente, a infiltração da musculatura glútea ${ }^{5}$. A realização de biópsia transretal encontra-se proscrita visto que este procedimento viola as barreiras anatômicas e favorece a invasão da mucosa retal pelo tumor ${ }^{9}$.

Devido à sua localização junto a estruturas nobres, a ressecção do cordoma expõe o cirurgião a um dilema na escolha da melhor estratégia cirúrgica:

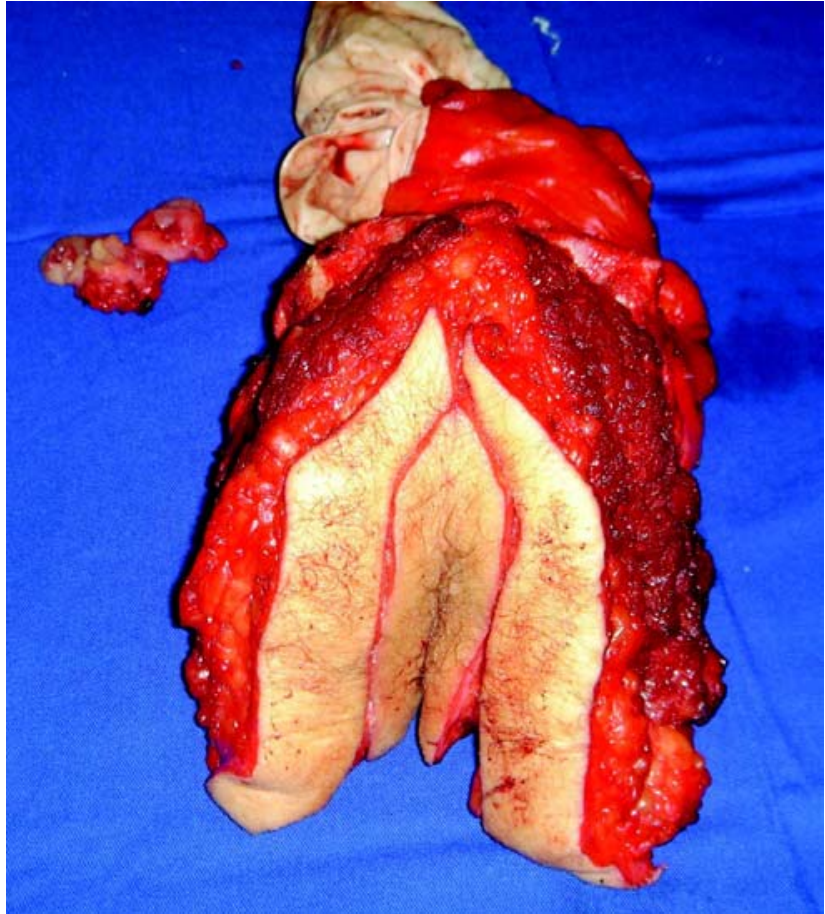

Figura 3 - Peça cirúrgica retirada em monobloco contendo pele, tecido celular subcutâneo, musculatura da região glútea, cóccix, sacro (S5, S4 e S3) e reto.

ressecção subtotal com piora da sobrevida ou excisão agressiva com aumento das morbidades motora, urinária e na função sexual. Atualmente, os cirurgiões têm optado pela ressecção completa da lesão, tendo em vista que a recidiva tumoral vem acompanhada da sintomatologia ainda mais agressiva do que a decorrente da denervação sacral intra-operatória ${ }^{3}$. Na escolha da via de acesso, a abordagem abdominossacral tem se mostrado a mais segura e de melhor exposição 7. A tentativa de preservação do reto, às custas de dissecção romba quando a massa pré-sacral encontra-se firmemente aderida, pode cursar com ruptura da pseudocápsula e disseminação de células tumorais, ou lesão da parede intestinal e contaminação do campo cirúrgico, ou, ainda, lesão dos vasos pré-sacrais e sangramento de difícil controle.

Stener e Gunterberg, em 1975, estabeleceram que a preservação do controle esfincteriano anal, da função urinária e da habilidade motora está diretamente relacionada com o nível de ressecção neural ${ }^{8}$. Eles afirmaram que, se pelo menos um terço dos nervos sacrais permanecerem intactos, a seqüela será mínima. Secções ao nível de S1 promovem incontinência anal, necessidade de cateterismo vesical intermitente e suportes externos de deambulação. Cerca de $50 \%$ 
dos pacientes submetidos a ressecções do nível de $\mathbf{S} 2$ para baixo evoluem sem alterações motoras e são capazes de manter bom controle intestinal e urinário.

A radioterapia não é utilizada como tratamento isolado devido às grandes dimensões do tumor ao diagnóstico. Está bem indicada após ressecções subtotais visto que sua função é promover o controle local da neoplasia. Parece não melhorar o prognóstico no pós-operatório das cirurgias com peças com margens livres de doença ${ }^{2}$. A quimioterapia tem se mostrado ineficaz no combate à recidiva tumoral.

O desenvolvimento do arsenal propedêutico, representado pelo advento da RM, e das novas técnicas cirúrgicas que surgiram a partir dos anos 60 e 70, preconizando ressecções mais agressivas, melhoraram significativamente a expectativa de vida dos pacientes portadores de cordoma, bem como o tempo de vida livre de doença. Na busca dessa cirurgia oncológica ideal, a abordagem multidisciplinaré essencial.

\footnotetext{
ABSTRACT: Chordoma is a rare malignant lesion of spinal cord originated from ectopic remnants of notocordial tissue. Its presentation is characterized by slow growth in spite of locally aggressive behaviour. We report a case of multidisciplinary oncologic resection with coloanal anastomosis. Extended and aggressive resections improved significantly the disease free survival in patients with chordoma. The multidisciplinary oncologic approach is essential in order to reach this goal.
}

Key words: Chordoma sacrococcygeal; multidisciplinary approach.

\section{REFERÊNCIAS}

1. Samson IR, Springfield DS, Suit HD. Operative treatment of sacrococcygeal chordoma: A review of twenty-one cases. J Bone Joint Surg Am 1993; 75:1476-84.

2. York JF, Kaczaraj A, Abi-Said D. Sacral chordoma: 40-year experience at a major cancer center. Neurosurgery 1999;44:7480.

3. Kaiser T, Pritchard D. Clinicopathologic study of sacrococcygeal chordoma. Cancer 1984, 53: 2574-8.

4. Rich TA, Schiller A, Suit HD. Clinical and pathologic review of 48 cases of chordoma. Cancer 1985;56:182-7.

5. Yamaguchi K, Tatezaki S, Satoh T. The usefulness of MRI in the surgical treatment of the sacral chordoma. Rinsho Seikei Geka 1994;29:959-64.
6. Chandawarkar RY, Rajiv Y. Sacrococcygeal chordoma: review of 50 consecutive patients. World J Surg 1996;20:717-9.

7. Gunterberg B, Norlen L, Stener B. Neurological evaluation after resection of the sacrum. Invest Urol 1975;13:183-8.

8. Localio SA, Eng K, Ranson JH. Abdominosacral approach for retrorectal tumors. Ann Surg 1980;191:555-60.

9. Fourney DR, Gokaslan ZL. Current managemet of sacral chordoma. Neurosurg Focus 2003;15:1-5.

Endereço para correspondência:

FÁBIO LOPES DE QUEIROZ

Rua Paracatú, 838 sala 506- Barro Preto

30.180-090- Belo Horizonte (MG) - Brasil

E-mail: fabiolopesq@ @otmail.com

Tel: (31) 3291-2064

Cel: (31) 9959-3979 